\title{
Editorial
}

\section{Give a dog a bad name}

$\mathrm{D}$ oes Antarctic research have a bad name? The short answer in some quarters is, 'Yes'. But why should this be so? Antarctica is an exciting and stimulating place to work and, whatever one's field of science, because of the continent's present-day isolated position, its massive ice cover and its previous key location within the ancient Gondwana supercontinent, it holds many important clues and answers to questions about our planet and its environment. Yet, those of us who are required to submit our science to peer review are sometimes perplexed by incomprehensible and unreasonably negative comments that come from outside. Are these non-Antarctic scientists just jealous, or do they have a point?

For some, it is certainly a complete lack of understanding of how Antarctic funding works. They could not care less about Antarctica and imagine that, if they could bring an end to the supposedly 'fabulous' sums devoted to Antarctic research, that money could be redeployed towards their own fields, which are naturally of much greater importance. But they would be wrong! In most countries, Antarctic funding is a specific allocation by government. If withdrawn, it would simply go back to the Treasury to be used for funding road sweeping, or some similar key activity of civilized life. It certainly seems most unlikely that science in general would benefit from such a change in policy. In any case the sums involved would make little difference on a national scale.

For anyone who cares to take a dispassionate view of Antarctic research as a whole it is all too obvious that there is a not inconsiderable quantity of poorly formulated, low-quality science being undertaken. Examples of this are apparent in the South Shetland Islands area, where numerous bases have been established over the last decade, more to gain a foothold in Antarctica than with a carefully conceived science plan in mind. However, there are examples from all over Antarctica. The question, 'My country has just granted [a significant sum of] money to fund a base and a scientific programme in Antarctica; what research should I do?', has actually been asked of an established Antarctic scientific operator.

All too often the activities, which stem from such initiatives, are led by politics and not by science, and not infrequently they result in repetitive research of poor quality, published in literature of doubtful standing. Yet, this need not be so. It does not matter how limited the resources, every scientist ought to be capable of contributing original thought and ideas. Even where the research is of good quality there are numerous instances of the scientists failing to publish the data in full thus negating the resource investment.

There are three messages here. For the governments, make sure you use some form of independent review to ensure you spend your money wisely on good science. For the reviewers, try admitting to yourself that good Antarctic research is as exciting, stimulating and valuable as any other field of science, but might just be logistically more difficult than some, and for the scientists, don't give the reviewers any cause but to believe otherwise.

Michael R.A. THOMSON 